\title{
Cephalic phase of gastric secretion in healthy subjects and duodenal ulcer patients: role of vagal innervation
}

\author{
S. J. KONTUREK ${ }^{1}$, N. KWIECIEN, W. OBTUlOWICZ, E. MIKOS, E. Sito, \\ J. OLEKSY, AND T. POPIELA \\ From the Institute of Physiology and Department of Surgery, Medical Academy, Krakow and District \\ Hospital, Krakow, Poland
}

SUMMARY In 10 healthy subjects and 25 duodenal ulcer patients, gastric acid and pepsin and serum gastrin responses to cephalic-vagal stimulation induced by modified sham-feeding (MSF) were studied before and after vagotomy and atropinisation and compared with those to maximal stimulation with pentagastrin. When the MSF-induced peak acid output was normalised as a percentage of peak response to pentagastrin it was about $62 \%$ in healthy subjects and $66 \%$ in duodenal ulcer patients. Serum gastrin concentration was not changed significantly by modified sham-feeding either in normal subjects or in duodenal ulcer patients. Truncal vagotomy completely abolished gastric acid and pepsin responses to MSF in duodenal ulcer patients. Atropine almost completely suppressed gastric acid and pepsin responses to MSF in healthy subjects and reduced those in duodenal ulcer patients by about $62 \%$. The combination of the modified sham-feeding and pentagastrin infusion resulted in augmentation of the acid output in duodenal ulcer patients but not in healthy subjects. This study shows that the cephalic phase results in a potent gastric acid and pepsin stimulation which is not accompanied by any change in serum gastrin concentration either in healthy subjects or duodenal ulcer patients and which is abolished by vagotomy and suppressed by atropine.

Physiological vagal excitation accomplished by the 'chew and spit' method was reported to induce a potent gastric secretory stimulation which was shown to be of similar magnitude to that attained by a real sham feeding technique (Stenquist et al., 1976). Using this modified sham-feeding (MSF) technique (Mayer et al., 1974), found that duodenal ulcer patients show both gastric acid and serum gastrin responses to cephalic stimulation, while normal subjects exhibit only an acid response without any change in serum gastrin level. Richardson et al. (1977) reported recently that modified sham-feeding in normal subjects failed to increase serum gastrin, though it caused marked gastric acid stimulation and augmentation of acid secretion induced by gastric distension but not by pentagastrin. No comparative studies on duodenal ulcer patients were included in this report.

The present study was designed (1) to determine the relative secretory potency of cephalic-vagal

1 Address correspondance: Professor Dr. S. J. Konturek, Institute of Physiology, ul. Grzegórzecka 16, 31-531 Kraków, Poland.

Received for publication 16 May 1979. stimulation of gastric secretion in healthy subjects and duodenal ulcer patients; (2) to examine the role of the vagal innervation and gastrin in gastric response to modified sham-feeding; (3) to measure the extent to which cephalic stimulation affects the gastric secretion induced by pentagastrin.

\section{Methods}

Ten healthy male subjects (mean age 20 years, range $19-22$ years; mean weight $68 \mathrm{~kg}$, range $64-73 \mathrm{~kg}$ ) and 25 male patients (mean age 21 years, range 19-24 years; mean weight $66 \mathrm{~kg}$, range $62-78 \mathrm{~kg}$ ) with wellestablished chronic duodenal ulcer disease were repeatedly examined. Ten of these patients were in clinical remission when their study period began; 10 others who had typical duodenal ulcer symptoms were examined before and after truncal vagotomy and pyloroplasty. The study was approved by a Human Research Review Committee and informed consent was obtained from each subject. The patients received no anticholinergics or $\mathbf{H}_{2}$-blockers for at least five days before the secretory studies were started. 
SECRETORY PROCEDURE

A fast of at least 14 hours preceded each test: studies were not conducted more frequently than twice a week. In all tests a double-lumen Dreiling tube was inserted and a few hours later positioned under fluoroscopic control with the tip at the junction of the third and fourth parts of the duodenum. A paediatric endotracheal tube cuff mounted over the Dreiling tube was placed midway between the gastric and duodenal orifices. At the beginning of each study the cuff was inflated with $20 \mathrm{ml}$ of air to prevent the reflux of duodenal content into the stomach or the escape of gastric juice into the duodenum as described previously (Konturek et al., 1975). The volumes of gastric aspirates were recorded and the acidity of gastric juice was measured by titrating $0.2 \mathrm{ml}$ samples with $0.1 \mathrm{~N} \mathrm{NaOH}$, using an automatic titrator (Autoburet, Radiometer, Copenhagen, Denmark). Acid outputs were expressed in millimoles (mmol) per 15 minutes. The pepsin concentration in the gastric juice was determined using a modification (Northrop et al., 1948) of the Anson haemoglobin method (Anson, 1938) and expressed as $\mathrm{mg}$ pepsin per $\mathrm{ml}$ by reading the absorbency of the trichloroacetic acid supernatant at $280 \mathrm{~nm}$ and comparing it with standards incubated with different concentrations of pepsin solutions (three times crystallised, Pentax Biochemicals, Kankakee, Illinois). Pepsin outputs were calculated, taking into consideration the dilution of the samples, and expressed as mg pepsin per 15 minutes.

\section{EXPERIMENTAL DESIGN}

Several series of secretory tests were performed using modified sham-feeding alone, MSF combined with intravenous infusion of atropine $(20 \mu \mathrm{g} / \mathrm{kg}-\mathrm{h})$ or pentagastrin $(2 \mu \mathrm{g} / \mathrm{kg}-\mathrm{h})$ or MSF performed before and after truncal vagotomy and pyloroplasty.

Modified sham-feeding was performed during a 30 minute period; the subjects chewed and totally expectorated an appetising meal consisting of $250 \mathrm{~g}$ beef steak, $150 \mathrm{~g}$ french fried potatoes, and $250 \mathrm{ml}$ water. All meals were prepared in a separate building so that the subjects could not see or smell the food until time for modified sham-feeding. Each subject was trained in a preliminary study not to swallow food during the test. During all tests gastric aspirates were carefully checked for swallowed food particles and none was found. In addition, phenol red was added to the $250 \mathrm{ml}$ water, part of the modified shamfeeding meal, and gastric samples were analysed for phenol red and, again, none was found. Phenol red concentration in each sample was measured spectrophotometrically at $575 \mathrm{~nm}$ after being alkalised to pH 11.5. In control tests for modified sham-feeding, the subjects chewed a piece of plastic tubing for $\mathbf{3 0}$ minutes.

In studies with atropine, an intravenous infusion of atropine sulphate was given in a constant dose of $20 \mu \mathrm{g} / \mathrm{kg}$-h throughout the secretory tests. The infusion of atropine was always started 30 minutes before the modified sham-feeding and all subjects tested experienced unpleasant side-effects including dryness of the mouth, difficulty in accommodation, and increase in the heart rate.

In studies with pentagastrin, an intravenous infusion of the peptide (Peptavlon, Ayerst Laboratories, New York) was given in a constant dose of $2 \mu \mathrm{g} / \mathrm{kg}$-h throughout the test to achieve the maximal acid output (Konturek et al., 1968). A steady state of acid secretion was usually achieved by the end of the first 30 minutes of pentagastrin infusion. Modified sham-feeding was superimposed on the continuing pentagastrin infusion. As a control for the feeding the subjects chewed a piece of plastic tubing for 30 minutes during pentagastrin infusion.

In studies on duodenal ulcer patients submitted to truncal vagotomy and pyloroplasty, the modified sham-feeding was performed before and about four

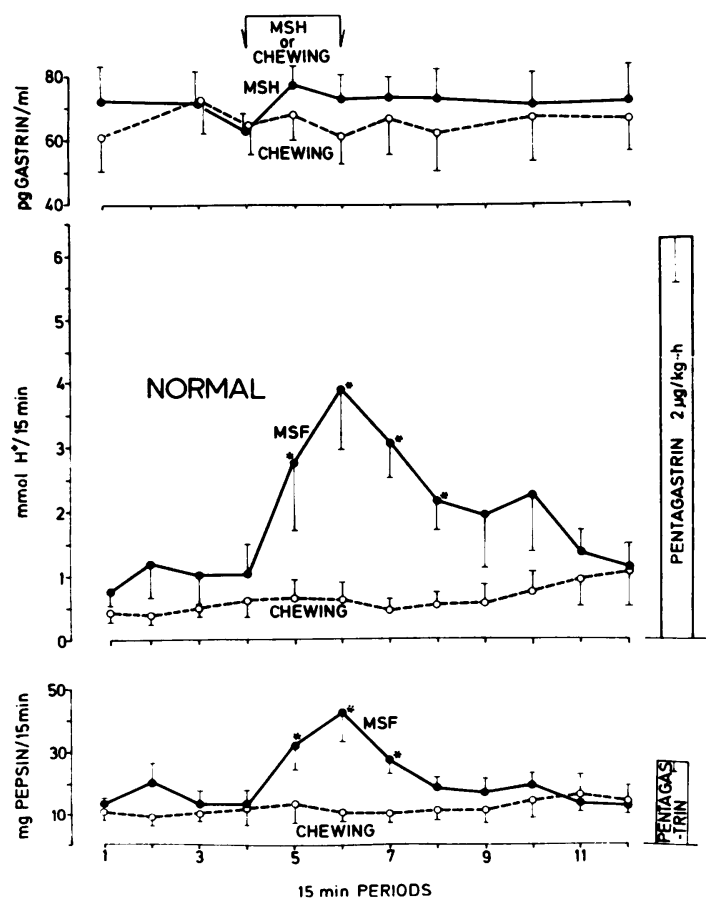

Fig. 1 Acid and pepsin outputs and serum gastrin concentrations in 10 normal subjects in the basal state and during and after 30 minutes of MSF or chewing a plastic tube. In this and subsequent figures vertical bars are standard errors of the mean SEM. Asterisks indicate significant $\mathrm{P}<0.05 \mathrm{~g}$ increase above control value. 
weeks after the surgery. In all these patients, vagotomy was complete as judged by the insulin tests performed about 10 days after the operation. The dose of insulin was $0.2 \mathrm{U} / \mathbf{k g}$ injected intravenously, and the response was judged to be 'positive' or 'negative' by multiple criteria (Gillespie et al., 1972).

\section{Serum gastrin}

In all tests except those with pentagastrin, venous blood samples were obtained from a peripheral vein at 15,30 , and 60 minutes before the modified shamfeeding and then at 15,30,45, 60, 90, and 120 minutes after it. Serum gastrin was measured by radioimmunoassay (Yalow and Berson, 1970). Antibody to gastrin (rabbit antiserum 4562 kindly provided by Professor J. F. Rehfeld of Aarhus, Denmark) was used at final dilution 1:100 000. With this antibody human heptadecapeptide gastrins (G-17-I and G-17-II) and human big gastrins (G-34-I and G-34-II) are measured on nearly equimolor basis G-34 being approximately two-thirds as immunoreactive as G-17. All determinations of gastrin were performed in duplicate. The within-assay variation was $9 \%$ and interassay variation was $16 \%$. The immunoassay system was sufficiently sensitive to detect $5 \mathrm{pg} / \mathrm{ml}$ of serum gastrin.

\section{STATISTICAL EVALUATION OF RESULTS}

Results are expressed as the mean \pm SEM. Student's $t$ test was used to determine the significance of difference between the means, with differences giving a $P$ value of less than 0.05 being considered significant (Siegal, 1956).

\section{Results}

COMPARISON OF GASTRIC ACID RESPONSES TO MSF IN HEALTHY SUBJECTS AND DUODENAL ULCER PATIENTS

Gastric acid and pepsin secretion in healthy subjects and duodenal ulcer patients under basal conditions and in response to modified sham-feeding is shown in Figs. 1 and 2. Acid and pepsin outputs were fairly stable during the 60 minutes of basal state, though they tended to reach higher values in duodenal ulcer than in healthy subjects. In control tests with chewing plastic tubing, gastric secretion did not show any significant change in either group of subjects. The mean peaks of acid outputs during the modified sham-feeding in healthy subjects and duodenal ulcer patients amounted to about $62 \%$ and $66 \%$ of the pentagastrin maximum, respectively. This difference in acid secretory response to modified sham-feeding between the two groups was not statistically significant. Modified sham-feeding resulted also in a marked rise in pepsin secretion
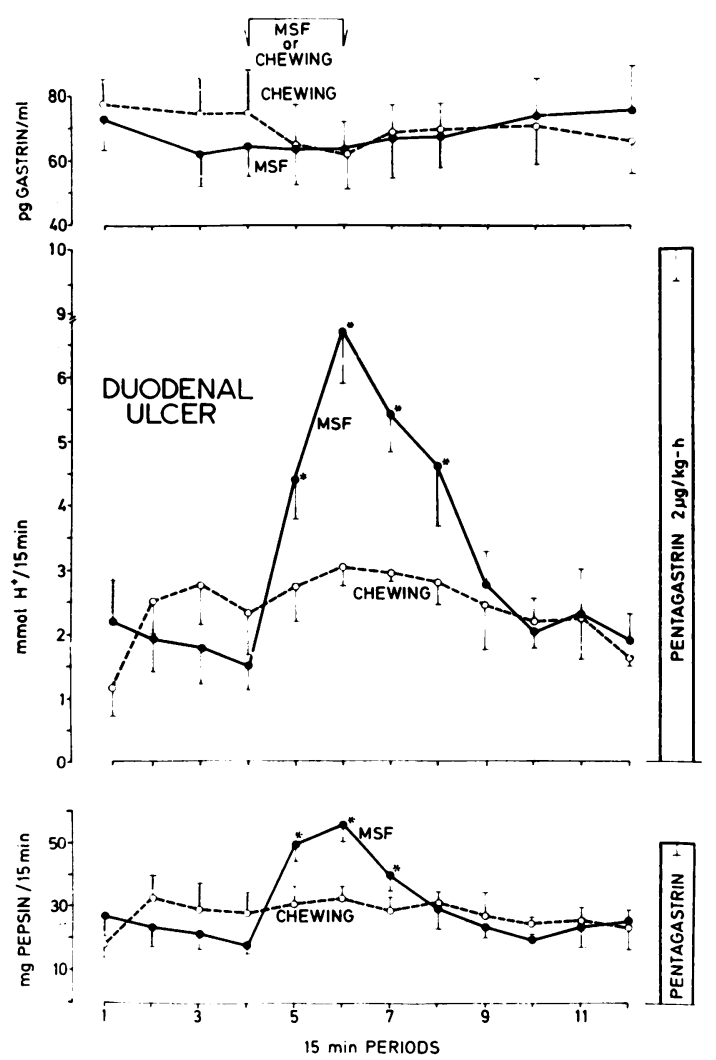

Fig. 2 Acid and pepsin outputs and serum gastrin concentrations in 10 duodenal ulcer patients in the basal state and during and after 30 minutes of MSF or chewing a plastic tube.

similar to that obtained with pentagastrin but again the difference between normal subjects and duodenal ulcer patients was not statistically significant. Serum gastrin response to modified sham-feeding in normal subjects and duodenal ulcer patients are presented in Figs. 1 and 2. No significant change in serum gastrin levels was observed during or after modified shamfeeding in both groups of subjects.

EFFECT OF ATROPINE ON BASAL AND MSF-INDUCED GASTRIC SECRETION

Atropine infused intravenously in a constant dose of $20 \mu \mathrm{g} / \mathrm{kg}-\mathrm{h}$ throughout the experiment resulted in almost complete inhibition of basal acid and pepsin secretion in healthy subjects (Fig. 3). During and after the modified sham-feeding both acid and pepsin outputs showed a tendency to small increase but this was not statistically significant. In contrast, atropinised duodenal ulcer patients responded to the sham-feeding with a significant increment in both acid and pepsin outputs which reached about $38 \%$ of 


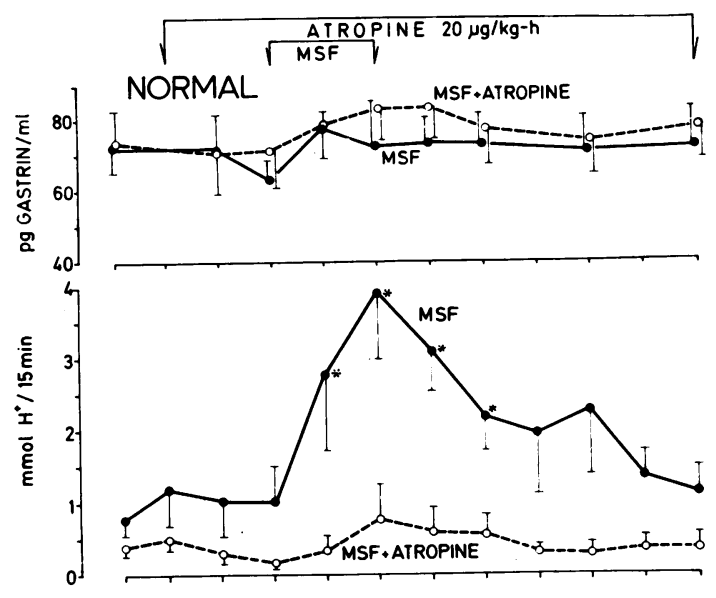

in both acid and pepsin secretion but without significant change in serum gastrin level (Table). After vagotomy modified sham-feeding did not affect significantly gastric acid or pepsin secretion. Basal serum gastrin concentration, which was raised in all vagotomised patients, was not significantly changed by sham-feeding (Table 1).

\section{Discussion}

Cephalic-vagal stimulation has been recognised as playing an important role in gastric secretory mechanisms ever since it was first demonstrated in Pavlov's laboratory that sham-feeding in the dog with intact vagal nerves results in copious and prolonged gastric acid and pepsin secretion. In addition to direct vagal stimulation of the oxyntic glands, vagal release

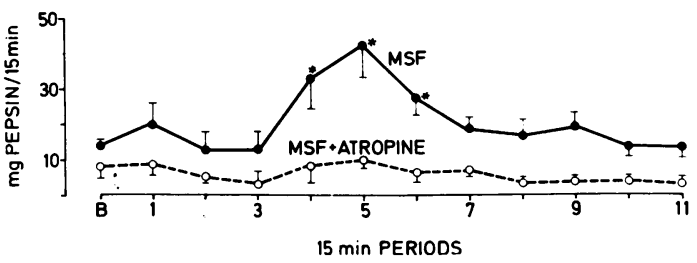
of gastrin has been implicated in the cephalic phase since Uvnas (1942) demonstrated in his classic

Fig. 3 Effect of atropine $20 \mu \mathrm{g} / \mathrm{kg}-\mathrm{h}$ on basal and MSFinduced acid and pepsin secretion and serum gastrin concentrations in 10 normal subjects.

that observed after modified sham-feeding in the same patients without atropinisation. Serum gastrin concentrations observed after atropine infusion were not significantly affected in healthy subjects (though they showed a tendency to increase), but they were significantly raised above control values in duodenal ulcer patients (Figs. 3 and 4).

\section{EFFECT OF MSF ON PENTAGASTRIN-INDUCED GASTRIC SECRETION}

Modified sham-feeding superimposed on pentagastrin-induced gastric secretion caused small but significant increase in acid output in healthy subjects and a marked and significant rise in acid output in duodenal ulcer patients (Fig. 5). Pepsin outputs in response to modified sham-feeding combined with pentagastrin were not significantly different from those obtained with pentagastrin alone.

\section{EFFECT OF VAGOTOMY ON MSF-INDUCED GASTRIC SECRETION}

Gastric acid and pepsin secretion as well as serum gastrin levels in response to modified sham-feeding in patients with symptomatic duodenal ulcer disease showed changes similar to those described previously (Fig. 2) in asymptomatic duodenal ulcer patients. The modified sham-feeding resulted in a marked rise

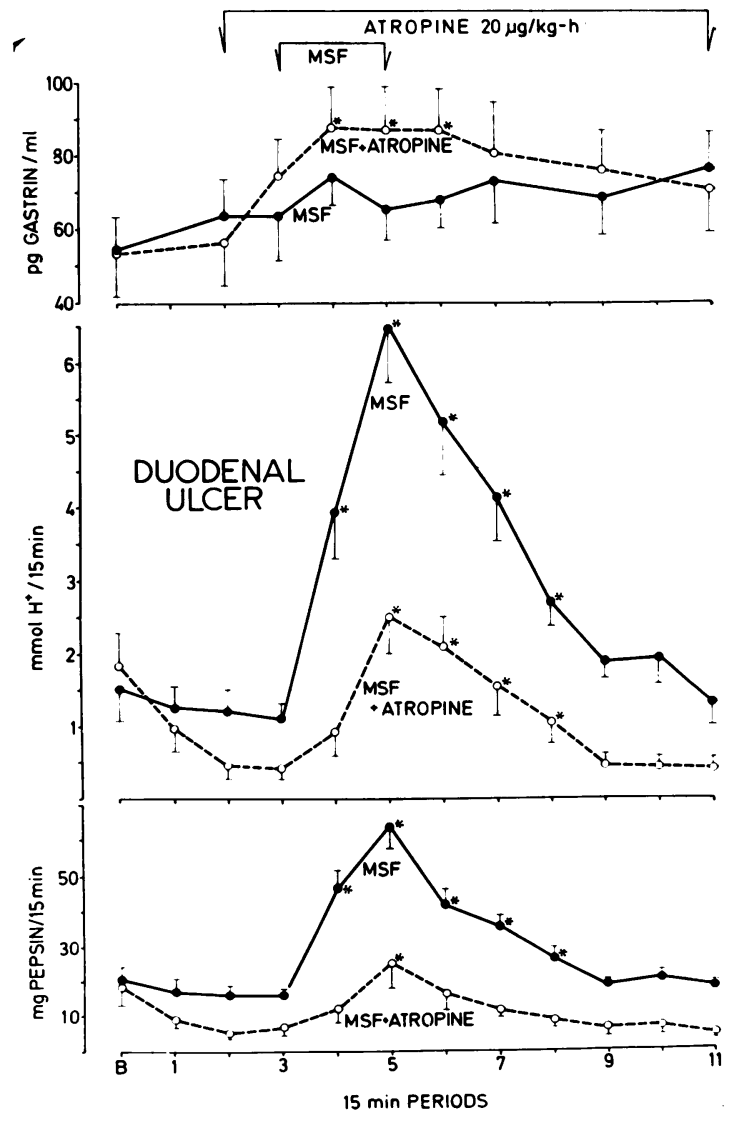

Fig. 4 Effect of atropine $20 \mu \mathrm{g} / \mathrm{kg}$ - $h$ on basal and MSFinduced acid and pepsin secretion and serum gastrin concentrations in 15 duodenal ulcer patients. 
Table Gastric acid outputs and serum gastrin responses to MSF in duodenal ulcer patients before and after truncal vagotomy and pyloroplasty

\begin{tabular}{|c|c|c|c|c|c|c|c|c|c|c|c|c|c|c|}
\hline \multirow[t]{2}{*}{ Type of test } & \multicolumn{5}{|c|}{ Acid outputs (nmol/30 min) } & \multicolumn{9}{|c|}{ Serum gastrin $(p g / m l)$} \\
\hline & \multicolumn{5}{|c|}{ Time (min) } & \multicolumn{9}{|c|}{ Time (min) } \\
\hline $\begin{array}{l}\text { Before vagotomy } \\
\text { MSF } \\
\text { Control } \\
\text { (chewing) } \\
\text { After vagotomy } \\
\text { MSF } \\
\text { Control } \\
\text { (chewing) }\end{array}$ & $\begin{array}{r}4 \cdot 73 \\
\pm 0 \cdot 45 \\
5 \cdot 32 \\
\pm 0 \cdot 42 \\
2 \cdot 10 \\
\pm 0 \cdot 28 \\
2 \cdot 36 \\
\pm 0.38\end{array}$ & $\begin{array}{r}4.32 \\
\pm 0.38 \\
4.04 \\
\pm 0.38 \\
1.97 \\
\pm 0.31 \\
2.23 \\
\pm 0.52\end{array}$ & $\begin{array}{r}12.52 \dagger \\
\pm 1.67 \\
4.72 \\
\pm 0.37 \\
1.56 \\
\pm 0.32 \\
1.98 \\
\pm 0.29\end{array}$ & $\begin{array}{r}11.45 \dagger \\
\pm 1.45 \\
4.05 \\
\pm 0.45 \\
2.32 \\
\pm 0.36 \\
2.31 \\
\pm 0.36\end{array}$ & $\begin{array}{r}6.85 \\
\pm 0.67 \\
4.76 \\
\pm 0.52 \\
2.64 \\
\pm 0.41 \\
2.65 \\
\pm 0.31\end{array}$ & $\begin{array}{r}65 \\
\pm \quad 7 \\
65 \\
\pm 9 \\
98 \\
\pm 12 \\
105 \\
\pm 17\end{array}$ & $\begin{array}{r}72 \\
\pm \quad 6 \\
61 \\
\pm \quad 7 \\
106 \\
\pm 9 \\
98 \\
\pm 12\end{array}$ & $\begin{array}{r}68 \\
+\quad 9 \\
72 \\
\pm \quad 5 \\
98 \\
\pm 10 \\
113 \\
\pm 12\end{array}$ & $\begin{array}{r}74 \\
\pm 12 \\
76 \\
\pm 8 \\
112 \\
\pm 14 \\
108 \\
\pm 18\end{array}$ & $\begin{array}{r}70 \\
\pm \quad 8 \\
79 \\
\pm 11 \\
105 \\
\pm 16 \\
120 \\
\pm 21\end{array}$ & $\begin{array}{r}73 \\
+8 \\
67 \\
+\quad 6 \\
98 \\
+13 \\
97 \\
+11\end{array}$ & $\begin{array}{r}68 \\
\pm \quad 4 \\
70 \\
\pm 8 \\
103 \\
\pm 9 \\
107 \\
\pm 13\end{array}$ & $\begin{array}{r}68 \\
\pm \quad 4 \\
72 \\
\pm 10 \\
112 \\
\pm 12 \\
103 \\
\pm 10\end{array}$ & $\begin{array}{r}66 \\
+8 \\
68 \\
\pm \quad 7 \\
107 \\
\pm 14 \\
108 \\
\pm 17\end{array}$ \\
\hline
\end{tabular}

*Periods of time when MSF was performed.

tsignificant $(P<0.05)$ increase above the control value.

experiments on cats that antrectomy can abolish or markedly reduce the gastric response to electrical stimulation of the vagal nerves.

There is little doubt that in man, as in animals, the cephalic phase is mediated entirely by the vagal nerves, and gastric secretion stimulated by shamfeeding in vagotomised patients has been recently proposed by Richardson and Feldman (1978) as a safe and reliable test for the completeness of vagotomy. Our study confirms that vagotomy completely abolishes gastric acid and pepsin response to
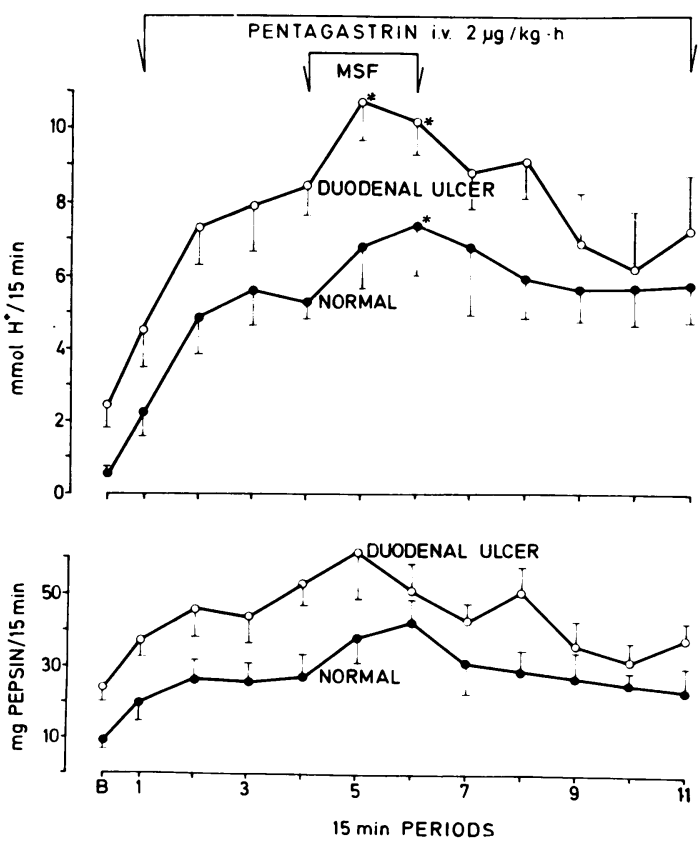

Fig. 5 Effect of MSF on maximally stimulated by pentagastrin acid and pepsin secretion in 10 normal and 10 duodenal ulcer patients. modified sham-feeding and that this test could, therefore be useful in examination of vagal function.

The mechanism of cephalic phase stimulation of gastric secretion, particularly the contribution of the direct vagal excitation of the parietal cells and of the vagal release of gastrin, has not yet been determined. Knutson et al., (1974), who investigated the effects of sham-feeding in duodenal ulcer patients before and after antrum-bulb resection, found that sham-feeding in duodenal ulcer patients increased gastric secretion up to about $55 \%$ of the maximal response to pentagastrin and resulted in a significant rise in serum gastric concentration. After antrum-bulb resection, the peak secretory response to sham-feeding decreased only to $32 \%$ of the pentagastrin maximum and no change in serum gastrin was observed. Recently, Richardson et al. (1977) reported that in normal subjects neither sham-feeding nor distension of the stomach with saline caused an increase in serum gastrin concentration, but that the two acting together raised the serum gastrin level and prolonged the acid secretory response. From these results it may be assumed that acid secretion evoked by cephalic-vagal excitation is due primarily to direct vagal stimulation of the oxyntic glands. The contribution of gastrin in the cephalic phase seems to be rather doubtful in normal subjects and non-essential in duodenal ulcer patients.

The results of our study are in good agreement with previous reports regarding the effect of MSF on gastric secretion (Mayer et al., 1974; Stenquist et al., 1976; Richardson et al., 1977) and show conclusively that cephalic-vagal stimulation results in a marked increase in acid and pepsin secretion both in healthy subjects and in duodenal ulcer patients. The increase in acid output (which in our duodenal ulcer patients reached about $66 \%$ of the pentagastrin maximum) is not dissimilar from the $55 \%$ of pentagastrin maximum which was observed by Knutson et al. 
(1974) utilising real sham-feeding in duodenal ulcer patients. The higher peak acid response to modified sham-feeding in duodenal ulcer patients as compared with that in normal subjects does not seem to reflect any more vigorous reaction of their stomachs to cephalic stimulation, as suggested by Mayer et al. (1974), but probably results from greater gastric secretory capacity as evidenced by the higher rates of pentagastrin-induced maximal acid secretion in these patients.

In contrast with previous reports (Knutson et al., 1974; Mayer et al., 1974) we failed to observe any significant change in the serum gastrin level during the modified sham-feeding either in duodenal ulcer patients or in healthy subjects. The reason for this discrepancy is not apparent. It may be due to failure to prevent the acid from the fundic mucosa from bathing the antral mucosa and to inhibit the release of antral hormone. Richardson et al. (1977), who maintained the intragastric $\mathrm{pH}$ at $5 \cdot 0$, were able to demonstrate a rise in serum gastrin in response to modified sham-feeding in normal subjects, but the possible role of gastric distension in this rise was not determined.

Since gastrin does not seem to contribute to the MSF-induced gastric stimulation, direct vagal excitation appears to be responsible. This excitation is mainly vagal, because it can be abolished by vagotomy, and cholinergic, because it can be suppressed by atropine. It is of interest that atropine in our study almost completely abolished MSFinduced gastric secretion in normal subjects but only partially inhibited it in duodenal ulcer patients. Perhaps the dose of atropine used was high enough to block the cholinergic system and to inhibit gastric secretion in healthy subjects but not in duodenal ulcer patients. Additional studies have to be performed to determine whether cephalic-vagal stimulation by modified sham-feeding in duodenal ulcer patients includes only a cholinergic component or whether also a non-cholinergic or cholinergic but atropine-resistant component is involved in this stimulation. It is noteworthy that atropine produces enhancement rather than inhibition of gastrin release in response to modified sham-feeding in duodenal ulcer patients. This may be considered as an evidence for cholinergic inhibition of gastrin release suggested previously (Walsh et al., 1971).

The next aspect of our study was designed to determine the extent to which modified sham-feeding augments acid and pepsin secretion induced by pentagastrin. It should be mentioned that modified sham-feeding in normal subjects was previously reported to augment gastric secretion induced by distension with saline and food, but not by pentagastrin (Richardson et al., 1977). Our study shows that maximally stimulated gastric acid secretion by pentagastrin can also be augmented by modified sham-feeding particularly in duodenal ulcer patients. The mechanism of this augmentation might best be explained by the interaction of pentagastrin with cholinergic and non-cholinergic stimuli activated by modified sham-feeding.

\section{References}

Anson, M. L. (1938). The estimation of pepsin, trypsin, papain and cathepsin with hemoglobin. Journal of General Physiology, 22, 78-79.

Gillespie, G., Elder, J. B., Smith, I. S., Kennedy, F., Gillespie, I. E., Kay, A. W., and Campbell, E. H. G. (1972). Analysis of basal acid secretion and its relation to the insulin response in normal and duodenal ulcer subjects. Gastroenterology, 62, 903-911.

Knutson, U., Olbe, L., and Ganguli, P. C. (1974). Gastric acid and plasma gastrin responses to sham feeding in duodenal ulcer patients before and after resection of antrum and duodenal bulb. Scandinavian Journal of Gastroenterology, 9, 351-356.

Konturek, S. J. (1976). Pathophysiology of gastric secretion. In Quadriennial Reviews: 10 International Congress of Gastroenterology, pp. 93-123. Edited by I. Magyar and I. Wittman. Okisz Labor Nyomda: Budapest.

Konturek, S. J., Biernat, J., Kwiecień, N., and Oleksy, J. (1975). Effect of glucagon on meal-induced gastric secretion in man. Gastroenterology, 68, 448-454.

Konturek, S. J., Wysocki, A., and Oleksy, J. (1968). Effect of medical and surgical vagotomy on gastric response to graded doses of pentagastrin and histamine. Gastroenterology, 54, 392-400.

Mayer, G., Arnold, R., Feurle, G., Fuchs, K., Ketterer, K., Track, N. S., and Creutzfeldt, W. (1974). Influence of feeding and sham feeding upon serum gastrin and gastric acid secretion in control subjects and duodenal ulcer patients. Scandinavian Journal of Gastroentero$\log y$, 9, 703-710.

Northrup, J. H., Kunitz, M., and Herriot, R. M. (1948). Crystalline Enzymes. Columbia University Press: New York.

Pavlov, I. P., and Schumowa-Simanowskaja, E. O., (1895). Beitrage zur Physiologie der Absonderungen. Archiv fur Anatomie und Physiologie Anat. Abt. p. 53.

Richardson, C. T., and Feldman, M. (1978). Sham feeding. A safe test for vagotomy (Abstract). Gastroenterology, 74, 1084.

Richardson, C. T., Walsh, J. H., Cooper, K. A., Feldman, M., and Fordtran, J. S. (1977). Studies on the role of cephalic-vagal stimulation in the acid secretory response to eating in normal human subjects. Journal of Clinical Investigation, 60, 435-441.

Siegel, A. (1956). Nonparametric Statistics for the Behavioral Sciences. McGraw-Hill: New York.

Stenquist, B., Knutson, V., and Olbe, L. (1976). Gastric acid responses to sham feeding and modified sham feeding in duodenal ulcer patients. Scandinavian Journal of Gastroenterology, 11, suppl. 38, 41. 
Uvnas, B. (1942). The part played by the pyloric region in the cephalic phase of gastric secretion. Acta Physiologica Scandinavica, 4, suppl. 13.

Walsh, J. H., Yalow, R. S., and Berson, S. A. (1971).
Effect of atropine on plasma gastrin response to feeding. Gastroenterology, 60, 16-21.

Yalow, R. S., and Berson, S. A. (1970). Radioimmunoassay of gastrin. Gastroenterology, 58- 1-14. 